\title{
Molecular and Epidemiologic Analysis of Reemergent Salmonella enterica Serovar Napoli, Italy, 2011-2015
}

\author{
Michela Sabbatucci, Anna Maria Dionisi, \\ Patrizio Pezzotti, Claudia Lucarelli, Lisa Barco, \\ Marzia Mancin, Ida Luzzi
}

Human infections with Salmonella enterica serovar Napoli are uncommon in Europe. However, these infections represented $5.9 \%$ of salmonellosis cases in Italy during 20142015. The source of infection is unknown. We analyzed surveillance data and compared strain genetic similarities and found that contaminated vegetables and surface water are probable sources of human infection.

Calmonella enterica serovar Napoli has attracted interSest since 1982, when chocolate contaminated with this serovar and imported from Italy caused 2 foodborne outbreaks $(1,2)$. During 2000-2006, a 140\% increase in Salmonella Napoli cases was reported in Europe (3), most (87\%) in France, Italy and Switzerland. Since 2004, the Rapid Alert System for Food and Feed (https://webgate.ec.europa. eu/rasff-window/portal/) has received 8 reports of Salmonella Napoli infection, which involved 6 countries and vegetables from Italy as the source of infection.

In Italy, sporadic cases of infection with Salmonella Napoli were reported before and after the first outbreak was reported in 1984 (4). The number of cases increased by 28\% during 2000-2011 (5). Recently, Salmonella Napoli has caused waterborne (6) and foodborne (7) outbreaks. Although studies in other countries (3) and Italy (8-10) investigated the mode of infection transmission, the zoonotic reservoir is still unknown.

To update epidemiologic trends for Salmonella Napoli in Italy, we identified the population at greatest risk for infection and defined putative vehicles of infection, which could assist possible control measures. We also analyzed 2011-2015 surveillance data for human, animal, environmental, food, and feed Salmonella Napoli isolates; evaluated associated factors; and compared genetic profiles.

Author affiliations: European Centre for Disease Prevention and Control, Stockholm, Sweden (M. Sabbatucci); Istituto Superiore di Sanità, Rome, Italy (M. Sabbatucci, A.M. Dionisi, P. Pezzotti, C. Lucarelli, I. Luzzi); Istituto Zooprofilattico Sperimentale delle Venezie, Padua, Italy (L. Barco, M. Mancin)

DOI: https://doi.org/10.3201/eid2403.171178

\section{The Study}

We extracted data on February 16, 2017, from the passive, voluntary, laboratory-based, surveillance system Enter-Net (http://www.iss.it/ente) for Salmonella spp. isolates from 2011-2015; patient identity was anonymous. Enter-Net is coordinated by the Istituto Superiore di Sanità (Rome, Italy) and contains information on strains from human and environmental samples. We excluded samples from nonhuman and nonenvironmental sources $(n=43)$, unspecified sample types $(\mathrm{n}=21)$, and undefined Salmonella serovars $(\mathrm{n}=1,066)$ from analysis. We obtained data (aggregated for 2011-2012 and 2013-2014) for Salmonella spp. isolated from food, animals, and feed by using the passive and voluntary veterinary surveillance system Enter-Vet (http://www. izsvenezie.it/temi/malattie-patogeni/salmonella/enter-vet/).

We evaluated potential epidemiologic risks associated with human and environmental Salmonella Napoli isolates and the 5 most frequent nontyphoidal Salmonella (NTS) serovars other than Napoli (monophasic variant of Typhimurium, Typhimurium, Derby, Enteritidis, and Infantis) by using simple 2-way frequency tables. Univariate analysis $(\mathrm{p}<0.05$ by $\chi^{2}$ test) was based on comparing categories for each variable and excluding missing values. We developed a multiple logistic regression model (Stata version 12; StataCorp LLC, College Station, TX, USA) to evaluate potential confounding among variables. We also used data for patients hospitalized with Salmonella Napoli infections or bacteremia as outcomes adjusted for other factors. The top 5 other NTS represented $73 \%$ of human Salmonella serovars isolated during 2011-2015. Results were consistent when we compared Salmonella Napoli with all reported NTS.

We serotyped Salmonella spp. isolates by using the White-Kauffmann-Le Minor scheme (11) and evaluated genetic relatedness among Salmonella Napoli isolates by using pulsed-field gel electrophoresis according to the PulseNet protocol (https://www.cdc.gov/pulsenet/ pathogens/protocols.html). We performed dendrogram and cluster analyses by using BioNumerics 7.5 (Applied Maths, Sint-Martens-Latem, Belgium). We scored similarity between chromosomal fingerprints by using the Dice coefficient and used the unweighted pair-group method with arithmetic means, $1.00 \%$ tolerance limit, $1.00 \%$ optimization, and coefficient of similarity $\geq 80 \%$ to define clonal relationships between strains. 
The monophasic variant of Typhimurium $(37.3 \%)$, Typhimurium (21.6\%), Enteritidis (9.3\%), Napoli (4.7\%), Derby $(3.1 \%)$, and Infantis $(1.9 \%)$ were the most frequent of 331 Salmonella serovars identified for 21,486 human records. The proportion of Salmonella Napoli cases increased from $4.3 \%$ in 2011 to $5.8 \%$ in 2015 ( $<<0.001$ ). Salmonella Napoli infection was more common in men, infants, children, and the elderly in northern and southern Italy during July-September than other reported serovars (Table 1). For Salmonella Napoli-infected patients with recent travel histories, those who traveled within Italy were more likely infected with this serovar (adjusted odds ratio $7.82,95 \%$ CI $1.00-61.25 ; \mathrm{p}=0.050$ ) than patients who traveled abroad. Although patients infected with Salmonella Napoli were hospitalized at rates similar to those infected with other serovars (Table 1), they had a greater risk for development of bacteremia (adjusted odds ratio 4.25, 95\% CI 3.07-5.88; $\mathrm{p}<0.001)$.

Among nonhuman isolates, 15,579 Salmonella spp. were reported (7,563 animal, 5,496 food, 2,078 environmental, and 442 feed). These isolates included 187 Salmonella Napoli (89 animal, 76 environmental, 21 food, and 1 feed).

Salmonella Napoli ranked fifth (3.7\%) among environmental Salmonella spp. and showed a significant increase from $1.6 \%$ in 2011 to $2.9 \%$ in $2015(\mathrm{p}<0.005)$. A total of $85 \%$ of Napoli isolates were from surface water. Multivariate analysis (Table 2) confirmed that Napoli strains were more commonly isolated during April-September $(p<0.001)$ and less commonly in northern and southern Italy than in central Italy.

Among Salmonella spp. animal isolates, the frequency of Salmonella Napoli increased from $0.7 \%$ in 2011 to $1.3 \%$ in 2015. A total of $50 \%$ of Napoli strains were obtained in the wild, most (70\%) from wild boars in northern Italy. The low proportion $(0.4 \%)$ from food remained stable during 2011-2015. Of 21 Napoli samples, 7 were from shellfish. One alfalfa sample contaminated with Napoli was reported in southern Italy in 2014.

We performed pulsed-field gel electrophoresis for 182 Salmonella Napoli strains isolated from different sources. We detected 121 unique profiles; 32 identical profiles contained 2-13 isolates. Despite high genetic variability among strains, we identified 4 main clusters that had genetic homologies $\geq 80 \%$ and matched the 3 areas in Italy: cluster A in northern Italy, cluster B in central Italy, and clusters C and D in southern Italy $(p<0.0001)$ (Figure). Most human and environmental isolates from northern Italy belonged to cluster A, and most in central Italy belonged to cluster $B(p<0.0001)$. In

\begin{tabular}{|c|c|c|c|c|c|}
\hline Characteristic & Serovar Napoli, no. (\%) & Other serovars, no. (\%) & Total & $p$ value & aOR $(95 \% \mathrm{Cl})$ \\
\hline \multicolumn{6}{|l|}{ Sex } \\
\hline M & $525(5.2)$ & $7,470(73.8)$ & 10,119 & \multirow[t]{3}{*}{0.001} & $1.17(1.02-1.35)$ \\
\hline $\mathrm{F}$ & $383(4.3)$ & $6,521(73.5)$ & 8,876 & & 1 \\
\hline Unknown & $111(4.5)$ & $1,757(70.5)$ & 2,491 & & $0.94(0.75-1.18)$ \\
\hline \multicolumn{6}{|l|}{ Age, y } \\
\hline$<1$ & $69(8.8)$ & $491(62.6)$ & 784 & \multirow[t]{5}{*}{$<0.001$} & $3.05(2.22-4.18)$ \\
\hline $1-14$ & $584(5.6)$ & $8,378(80.2)$ & 10,442 & & $1.57(1.28-1.92)$ \\
\hline $15-64$ & $127(3.1)$ & $2,667(65.6)$ & 4,063 & & 1 \\
\hline$\geq 65$ & $195(5.0)$ & $2,447(63.3)$ & 3,863 & & $1.76(1.39-2.22)$ \\
\hline Ūnknown & $44(1.9)$ & $1,765(75.6)$ & 2,334 & & $0.65(0.45-0.92)$ \\
\hline \multicolumn{6}{|c|}{ Geographic area } \\
\hline North & $893(5.1)$ & $12,708(73.0)$ & 17,397 & \multirow[t]{3}{*}{$<0.001$} & $1.77(1.43-2.20)$ \\
\hline Central & $102(3.0)$ & $2,540(74.1)$ & 3,428 & & 1 \\
\hline South & $24(3.6)$ & $500(86.4)^{\prime}$ & 661 & & $1.63(1.02-2.61)$ \\
\hline \multicolumn{6}{|c|}{ Time of sampling } \\
\hline Jan-Mar & $12(0.3)$ & $3,623(78.3)$ & 4,626 & \multirow[t]{4}{*}{$<0.001$} & 1 \\
\hline Apr-Jun & $203(4.4)$ & 3,356 (73.2) & 4,584 & & $17.98(10.02-32.26)$ \\
\hline Jul-Sep & $594(8.8)$ & $4,622(68.5)$ & 6,752 & & $38.00(21.41-67.44)$ \\
\hline Oct-Dec & $210(3.8)$ & $4,147(75.1)$ & 5,524 & & $15.15(8.45-27.17)$ \\
\hline \multicolumn{6}{|c|}{ Period of sampling } \\
\hline 2011-2013 & $643(4.3)$ & $11,152(73.9)$ & 15,081 & \multirow[t]{2}{*}{$<0.001$} & 1 \\
\hline 2014-2015 & $376(5.9)$ & $4,596(71.8)$ & 6,405 & & $1.4(1.22-1.61)$ \\
\hline \multicolumn{6}{|l|}{ Hospitalization } \\
\hline Yes & 368 (4.9) & $5,453(72.4)$ & 7,533 & \multirow[t]{3}{*}{0.583} & ND \\
\hline No & $358(4.9)$ & 5,533 (75.1) & 7,367 & & ND \\
\hline Unknown & $293(4.4)$ & 4,762 (72.3) & 6,586 & & ND \\
\hline \multicolumn{6}{|l|}{ Bacteremia } \\
\hline Yes & $962(4.6)$ & $15,527(74.1)$ & 20,962 & \multirow[t]{3}{*}{$<0.001$} & ND \\
\hline No & $57(10.9)$ & $221(42.2)$ & 524 & & ND \\
\hline Unknown & $6(4.9)$ & $75(61.0)$ & 123 & & ND \\
\hline Total & $1,019(4.7)$ & $15,748(73.3)$ & 21,486 & ND & ND \\
\hline
\end{tabular}


Table 2. Characteristics of environmental samples contaminated with Salmonella enterica serovar Napoli and samples with the 5 most common other nontyphoidal serovars, Italy 2011-2015*

\begin{tabular}{|c|c|c|c|c|c|}
\hline Characteristic & Serovar Napoli, no. (\%) & Other serovars, no. (\%) & Total & $p$ value & aOR $(95 \% \mathrm{Cl})$ \\
\hline \multicolumn{6}{|c|}{ Geographic area } \\
\hline Northern & $37(2.5)$ & $531(35.6)$ & 1,493 & $<0.001$ & $0.13(0.06-0.26)$ \\
\hline Central & $16(11.2)$ & $38(26.6)$ & 143 & & 1 \\
\hline Southern & $23(5.2)$ & $151(34.2)$ & 442 & 0.001 & $0.25(0.11-0.57)$ \\
\hline \multicolumn{6}{|c|}{ Time of sampling } \\
\hline Jan-Mar & $4(1.0)$ & $200(49.8)$ & 402 & & 1 \\
\hline Apr-Jun & $28(4.9)$ & $169(29.8)$ & 567 & $<0.001$ & $9.45(3.15-28.35)$ \\
\hline Jul-Sep & $30(4.7)$ & $153(24.2)$ & 632 & $<0.001$ & $10.8(3.62-32.25)$ \\
\hline Oct-Dec & $14(2.9)$ & $198(41.5)$ & 477 & $<0.05$ & $3.83(1.22-12.06)$ \\
\hline \multicolumn{6}{|c|}{ Period of sampling } \\
\hline 2011-2013 & $43(3.6)$ & $411(34.5)$ & 1,193 & & 1 \\
\hline 2014-2015 & $33(3.7)$ & 309 (34.9) & 885 & 0.066 & $0.59(0.33-1.04)$ \\
\hline Total & $76(100.0)$ & $720(100.0)$ & 2,078 & ND & ND \\
\hline
\end{tabular}

*The 5 most common other serovars were the monophasic variant of Typhimurium, Typhimurium, Derby, Enteritidis, and Infantis. aOR, adjusted odds ratio; ND, not determined.

southern Italy, all human strains isolated belonged to clusters A or $\mathrm{D}$, and $90 \%$ of environmental strains belonged to cluster $\mathrm{C}(\mathrm{p}<0.0001)$. The 4 isolates from vegetables in southern

Italy belonged to clusters A, C, and D. Seven profiles with genetic homologies $<80 \%$ were obtained from different sources in northern and southern Italy.

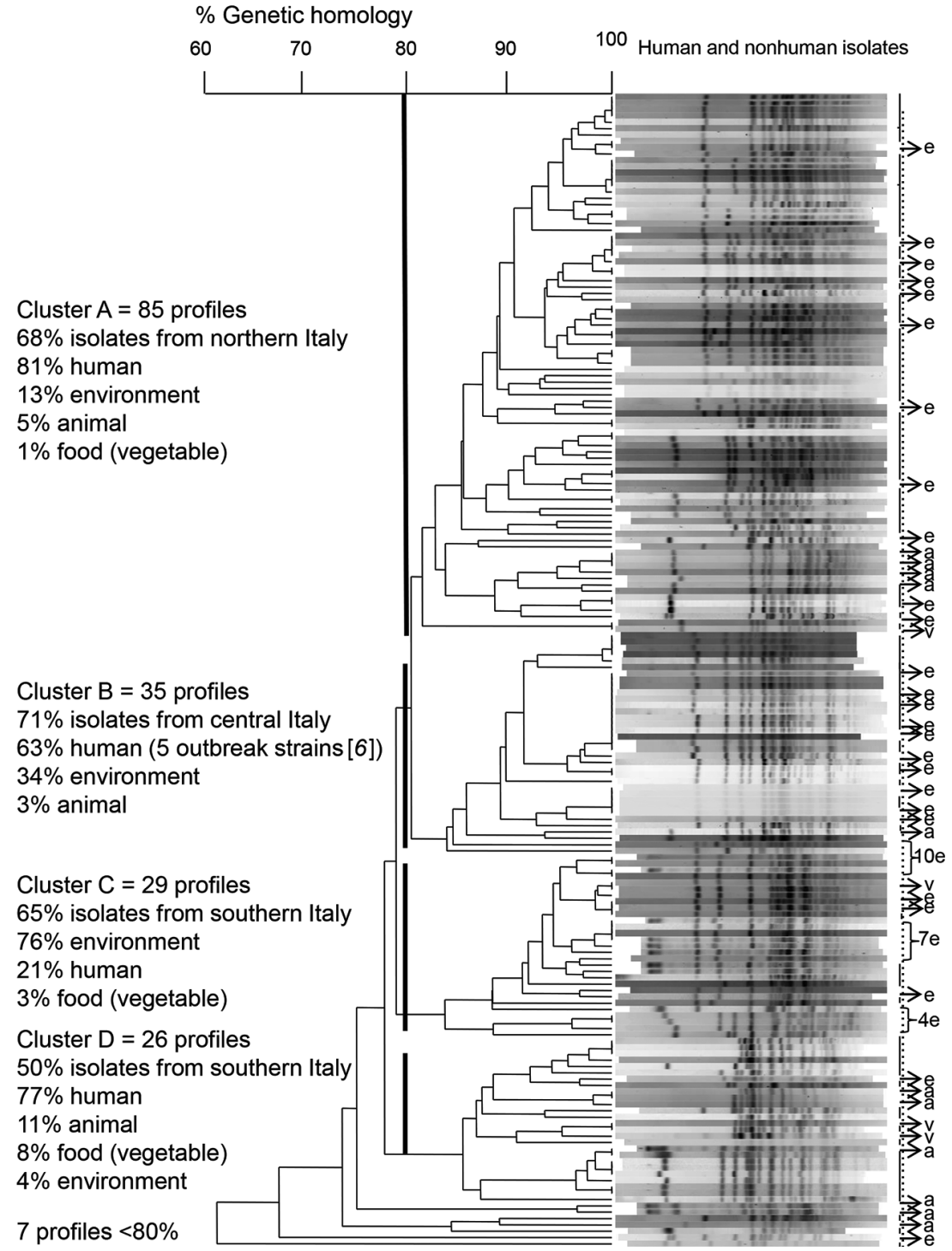

Figure. Dendrogram of 182 pulsed-field gel electrophoresis-based profiles of Salmonella enterica serovar Napoli strains isolated from human, environmental, animal, and food samples in Italy, 2011-2015. Four main clusters matched with the 3 main geographic areas in Italy (cluster A in northern Italy, cluster B in central Italy, and clusters $C$ and D in southern Italy). Genetic analysis was based on $80 \%$ homology. Human strains $(n=124)$ are indicated by a solid vertical line. e indicates environmental strains $(n=46)$, a indicates animal strains $(n=8)$, and $v$ indicates food (vegetable) strains $(n=4)$. 


\section{Conclusions}

Outbreaks of Salmonella Napoli infection reemerged in Italy during 2011-2015. In Italy, Salmonella Napoli patients accounted for $5.9 \%$ of salmonellosis cases reported during 2014-2015. Consistent with a study conducted in Italy (9), we found that surface water, including irrigative water, rather than animal food, was the main cause of infection with Salmonella Napoli. On the basis of an outbreak in Sweden (http://www. epinorth.org/eway/default.aspx?pid_230\&trg_Area 5328\&MainArea 5260 5328:0:\&4148 5326:58\&Ar ea $53285273: 46553:: 0: 5326: 574::: 0: 0)$, reports of the Rapid Alert System for Food and Feed on vegetables from Italy contaminated with Salmonella Napoli, and that the fact that $\approx 30 \%$ of irrigative surface water in Italy is used for vegetables (https://www.istat.it/it/files/2014/11/Utilizzo_risorsa_idrica.pdf), we believe that ready-to-eat vegetables irrigated with contaminated surface water are the main food vehicle for Salmonella Napoli.

Marked seasonality of cases matching environmental reports might be caused by increased irrigation and consumption of ready-to-eat vegetables during summer and fall, and more frequent human contact with contaminated surface water during summer and fall. We also reported frequent isolation of Salmonella Napoli from wild boars, which suggests a role for dissemination through the environment (12). Human and environmental strains of Salmonella Napoli belonging mainly to cluster A in northern Italy and cluster B in central Italy suggest direct infection. Different clusters for human and environmental strains from southern Italy might indicate wider spread in the environment.

Heterogeneous sampling of nonhuman isolates through Italy was a limitation of this study. Travel history within Italy, rather than abroad, of patients infected with Salmonella Napoli increases public health concern in Italy. Uncontrolled spread of Salmonella Napoli through the environment and associated foodborne and waterborne outbreaks, the increasing proportion of young patients, and high risks for development of bacteremia make infections with Salmonella Napoli a serious public health concern in Italy.

\section{Acknowledgments}

We thank all participants in the Enter-Net and Enter-Vet networks for providing information and strains, Annalisa Pantosti and Loredana Ingrosso for helpful suggestions, and Slawomir Owczarek and Ildo Benedetti for technical assistance.

This study was partially supported by a grant (Surveillance of Diseases Transmitted by Food and Water [Enter-Net]: adaptation of the Italian system to the European normative framework 1616-2014) from the Italian Ministry of Health.

\section{About the Author}

Dr. Sabbatucci is a scientist at the Italian National Institute of Health, Rome, Italy. Her primary research interest is improving public health regarding infectious diseases through applied microbiology and epidemiology.

\section{References}

1. Gizzarelli S, Salmaso S, Toti L, Zanoni D. Microbiologic investigation of chocolate contaminated with Salmonella Napoli [in Italian]. Nuovi Ann Ig Microbiol. 1983;34:347-52.

2. Gill ON, Sockett PN, Bartlett CL, Vaile MS, Rowe B, Gilbert RJ, et al. Outbreak of Salmonella napoli infection caused by contaminated chocolate bars. Lancet. 1983;1:574-7. http://dx.doi.org/10.1016/S0140-6736(83)92822-2

3. Fisher IS, Jourdan-Da Silva N, Hächler H, Weill FX, Schmid H, Danan C, et al. Human infections due to Salmonella Napoli: a multicountry, emerging enigma recognized by the Enter-Net International Surveillance Network. Foodborne Pathog Dis. 2009;6:613-9. http://dx.doi.org/10.1089/fpd.2008.0206

4. Costa E, Pontello M, Pedroni M, Penna L. Epidemiological investigation on the diffusion of $S$. enterica ser. Napoli through equine meat in the province of Brescia [in Italian]. Archivio Veterinario Italiano. 1986;37:115-22.

5. Graziani C, Luzzi I, Owczarek S, Dionisi AM, Busani L. Salmonella enterica serovar Napoli infection in Italy from 2000 to 2013: spatial and spatio-temporal analysis of cases distribution and the effect of human and animal density on the risk of infection. PLoS One. 2015;10:e0142419. http://dx.doi.org/10.1371/journal.pone.0142419

6. Zuliani M, Rocco G, Bruschetta G, Benedetti I, Owczarek S, Dionisi AM. Salmonella Napoli waterborne outbreak in a school in Italy. In: Abstracts of the European Scientific Conference on Applied Infectious Disease Epidemiology (ESCAIDE), Edinburgh, UK, October 24-26, 2012. Abstract no. 201288. p. 78 [cited 2017 Dec 13]. https://issuu.com/mstryk/docs/escaide-2012-abstract-book

7. Huedo P, Gori M, Amato E, Bianchi R, Valerio E, Magnoli L, et al. A multischool outbreak due to Salmonella enterica serovar Napoli associated with elevated rates of hospitalizations and bacteremia, Milan, Italy, 2014. Foodborne Pathog Dis. 2016;13:417-22. http://dx.doi.org/10.1089/fpd.2015.2091

8. Huedo P, Gori M, Zolin A, Amato E, Ciceri G, Bossi A, et al. Salmonella enterica serotype Napoli is the first cause of invasive nontyphoidal salmonellosis in Lombardy, Italy (2010-2014), and belongs to Typhi subclade. Foodborne Pathog Dis. 2017;14:14851. http://dx.doi.org/10.1089/fpd.2016.2206

9. Oggioni C, Fontana G, Pavan A, Gramegna M, Ferretti V, Piatti A, et al. Investigation of potential risk factors for Salmonella enterica subsp enterica serotype Napoli: a nested case-control study in Lombardia region [in Italian]. Ann Ig. 2010;22:327-35.

10. Graziani C, Mughini-Gras L, Owczarek S, Dionisi A, Luzzi I, Busani L. Distribution of Salmonella enterica isolates from human cases in Italy, 1980 to 2011. Euro Surveill. 2013;18:20519. http://dx.doi.org/10.2807/1560-7917.ES2013.18.7.20519

11. Guibourdenche M, Roggentin P, Mikoleit M, Fields PI, Bockemühl J, Grimont PA, et al. Supplement 2003-2007 (no. $47)$ to the White-Kauffmann-Le Minor scheme. Res Microbiol. 2010;161:26-9. http://dx.doi.org/10.1016/j.resmic.2009.10.002

12. Zottola T, Montagnaro S, Magnapera C, Sasso S, De Martino L, Bragagnolo A, et al. Prevalence and antimicrobial susceptibility of salmonella in European wild boar (Sus scrofa); Latium region, Italy. Comp Immunol Microbiol Infect Dis. 2013;36:161-8. http://dx.doi.org/10.1016/j.cimid.2012.11.004

Address for correspondence: Michela Sabbatucci, Istituto Superiore di Sanità, 00161 Rome, Italy; email michela.sabbatucci@iss.it 